\title{
Compressive and Flexural Strength of Concrete Containing Palm Oil Biomass Clinker with Hooked-End Steel Fibers
}

\author{
Mohd Haziman Wan Ibrahim $^{1 *}$, Sajjad Ali Mangi ${ }^{1 \& 2}$, Ridzuan M.B ${ }^{1}$, \\ Burhanudin M.K ${ }^{1}$, Norwati Jamaluddin ${ }^{1}$, Kok Hui Li ${ }^{1}$, Shahiron Shahidan ${ }^{1}$, \\ Khalid F.S ${ }^{1}$, Mohd Fadzil Arshad ${ }^{3}$, Ramadhansyah Putra Jaya ${ }^{4}$
}

\author{
${ }^{1}$ Faculty of Civil and Environmental Engineering, Universiti Tun Hussein Onn Malaysia, 86400 Batu Pahat, Johor, \\ Malaysia \\ ${ }^{2}$ Department of Civil Engineering, Mehran University of Engineering \& Technology, SZAB Campus Khairpur Mirs, \\ Sindh, Pakistan \\ ${ }^{3}$ Faculty of Civil Engineering, Universiti Teknologi Mara, 40450 Shah Alam, Selangor, Malaysia \\ ${ }^{4}$ Faculty of Civil Engineering and Earth Resources, Universiti Malaysia Pahang, 26300 Gambang, Pahang, Malaysia
}

Received 23 April 2018; accepted 11 December 2018, available online 31 December 2018

\begin{abstract}
This research was carried out to evaluate the influence of hooked-end steel fibers on compressive and flexural strength of concrete containing palm oil biomass clinker (POBC) as partial replacement of fine aggregates. The optimum percentage of POBC was taken as $10 \%$, to replace natural sand. Due to the porous characteristic of POBC, hooked-end steel fibers were added to improve the flexural strength of concrete. This research involves $10 \%$ of POBC with varying percentages of the hooked-end steel fibers i.e. $0.2 \%, 0.4 \%$ and $0.6 \%$ by weight was produced. Total 48 specimens were casted, 24 concrete cubes for compressive strength and 24 prisms were casted for flexural strength at 7 days and 28 days. Hence, it was evaluated that the reduction of workability of concrete with the addition of steel fibers. Furthermore, maximum flexural strength was recorded as $2.54 \mathrm{MPa}$ with $0.4 \%$ hooked-end steel fibers at 28 days and maximum compressive strength of was recorded as $27.51 \mathrm{MPa}$ with $0.6 \%$ hooked-end steel fibers at 28 days. It was concluded that the hooked-end steel fibers have good potentiality to enhance the compressive as well as flexural strength of concrete.
\end{abstract}

Keywords: Hooked-end steel fibers, palm oil biomass clinker, workability, compressive strength, flexural strength.

\section{Introduction}

Concrete is the chief material in construction, due to its versatility, durability and sustainability. It is categorized by brittle failure as it nearly completed loss of load sustaining capacity [1]. In order to reduce the shrinkage cracks and impart economy of concrete, aggregates play an important role in the mix design [2]. Natural sand is one of the major constituents' materials used in preparation of concrete and development of infrastructure [3]. This situation directed to the extensive use of natural sand, which is also an environmental concern. Therefore, researchers are intended to introduce new alternatives for the sustainable concrete construction. One of such solution is the application of industrial wastes in concrete such as palm oil biomass clinker [4] [5], fly ash [6-7], coal bottom ash [8-11], rice husk ash [12-14] and silica fume [17] in the production of concrete.

The palm oil biomass clinker (POBC) is a mineral by-product, produced from the burning of the palm oil fiber and kernel shells in the boiler [4]. This study considered POBC as fine aggregates in concrete. The particle size distribution of POBC ranging from $100 \mathrm{~mm}$ to $400 \mathrm{~mm}$, which indicates the suitability to be utilized as fine aggregates [15]. The literature review indicated that the replacement of sand with POBC resulted in decreasing the workability of concrete [4] [16] [17].In addition to that the compressive and flexural strength of concrete were observed as increasing with the incorporation of POBC in concrete [4]. Generally, excessive replacement level has produced porous concrete with lower strength concrete. Hence, to enhance the compressive and flexural strength of concrete, steel fibers were introduced into concrete [18].

It has been observed by Lee [19] that hooked-end steel fibers able to improve properties of concrete from brittle to ductile behavior of concrete structures. It was generally observed that hooked-end steel fibers are difficult to distribute uniformly in the concrete mixture and well distribution of fibers gives optimum benefits of hooked-end steel fibers [20]. Formerly 0.5 to $1.5 \%$ of steel fibers in concrete were used by the researchers [21]. Beside that the concrete has an advantage to prepared and fabricated easily in different shape in the structural 
systems. Therefore, concrete is popular and widely used material of construction in the world [22] Theoretically, in this research the hooked-end steel fibers were incorporated into the concrete containing $10 \%$ of POBC. The effects of hooked-end steel fibers on the fresh and hardened properties of concrete were investigated in this research.

\section{Previous Related Research}

Based on the previous studies, the concrete compressive strength was increased with the increasing of the palm oil biomass clinker [4] [16]. Typically, compressive strength of concrete was increased up-to 5 to $20 \%$ replacement level and reduction in compressive strength was observed when the replacement level more than 20\% [4] [5]. This is due to glassy surface texture of palm oil biomass clinker (POBC) led to the negative effect on cohesion between the particles [23] and due to pozzolanic reaction offered by $\mathrm{POBC}$ in concrete, which is able to improve the interfacial bond between the paste and aggregates.

Fibers is a small discrete reinforcing material to arrest the crack in concrete in order to overcome the weakness of concrete in tension [24]. Nowadays, various types of fibers were available in market with different shape and size which included glass fibers, steel fibers, natural and synthetic fibers. Steel fibers were used in this research to investigate the influence of fibers on hardened properties concrete. It can be obtained through wire was cut or chopped to required lengths. Different types of crimps, notch and shape of steel fibers was introduced in order to improve the mechanical bond of concrete [25] However, the addition of steel fibers into concrete mixtures could enhance the ductility, toughness, flexural, tensile and shear strength of concrete [26]. Steel fibers have many types such as hooked-end, end large, wave cut and deformed sheet steel fibers [25]. Hooked-end steel fibers were introduced in this study in order to reduce the brittle fracture of concrete when loads are applied [25]. Hooked-end steel fibers widely have high strengthening effect compared to other types of steel fibers. Furthermore, addition of fibers possibly reduces the severity of failure mode for concrete and the crack's width of concrete able to reduce when the presence of hooked-end steel fibers [25] [26]. This is because the development of micro-cracking and their propagation along the matrix was delay [18] as the pinching forces was applied at the tips of the crack.

The rise in compressive strength of concrete was recorded with additional of hooked-end steel fibers [23]. This is due to the internal passive confinement of the matrix by steel fibers that delays the spreading and propagation of crack. Meanwhile, some research [28] [26] have found that the compressive strength of concrete does not increased significantly with small amounts of hooked-end steel fibers added into concrete mixtures. Although the influence of hooked-end steel fibers on the flexural strength of concrete is greater than direct tension and compression [26]. Therefore, the flexural strength of concrete can be improved with hooked-end steel fibers added into concrete.

\section{Material and Methodology}

\subsection{Materials}

\subsubsection{Cement}

In this study, ordinary portland cement (grade 42.5) conforming to Malaysia Standard MS 197-7: 2007, was used.

\subsubsection{Course Aggregates}

The coarse aggregates collected from Muar, Johor, Malaysia. The coarse aggregate having size of $10 \mathrm{~mm}$ was selected for the research. After collection, the coarse aggregates were kept for dried drying purpose for several days to achieve saturated surface dry (SSD) condition. Thus, the coarse aggregates were sieved through $10 \mathrm{~mm}$ sieve size.

\subsubsection{Fine Aggregates}

The fine aggregate (sand) was collected through river sand from Kahang, Johor, Malaysia and air dried for 2 days in order to achieve saturated surface dry (SSD) conditions. Before the laboratory work, the sand was sieved through $5 \mathrm{~mm}$ sieve.

\subsubsection{POBC}

In this study, palm oil biomass clinker (POBC) as shown in Fig. 1 was used as fine aggregate at $10 \%$ from the total content of fine aggregate. in concrete. The selection of $10 \%$ replacement was based on the trial mix tests.

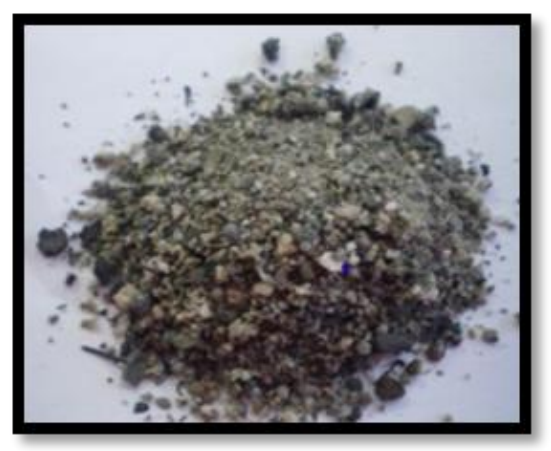

Fig. 1 Palm oil biomass clinker

\subsubsection{Steel Fibers}

Hooked-end steel fibers as shown in Fig.2, was supplied by Timuran Engineering Sdn Bhd. It is Group I (cold drawn wire) that conforms to BS EN 14889-1: 2006 and MS 2388: 2010 was used in concrete. Various percentages of the hooked-end steel fibers was added into concrete. 


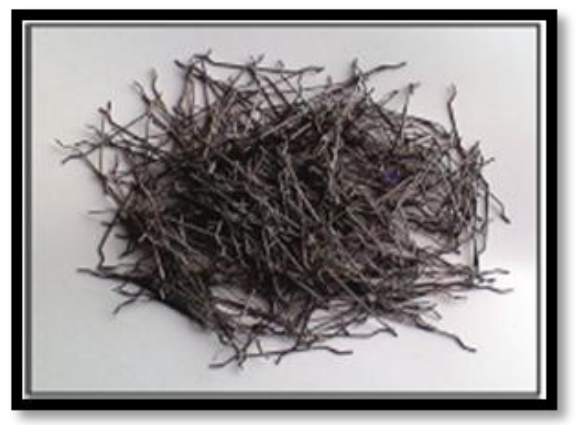

Fig. 2 Hooked-end steel fibers

\subsection{Experimental Work}

The concrete mix was prepared based on DOE method of concrete mix design at fixed water-to-cement ratio for all the samples as mentioned in Table 1 . In this research total 48 specimen were prepared as mentioned in Table 2. $10 \%$ POBC proportion was calculated with reference to the amount of fine aggregate (sand) and steel fibers proportion were calculated with reference to the total volume of the batch by weight method. Concrete cubes of size $100 \mathrm{~mm}$ were casted for compressive strength and prisms 100 in cross-section and $500 \mathrm{~mm}$ in length were casted for flexural strength. Raw materials testing has been done for sand and POBC i.e. Sieve analysis and specific gravity in to evaluate the physical characteristics and particle fineness. Furthermore, the curing period was observed as 7 and 28 days and samples were kept immersed in water.

Table 1 Concrete mix design $\left(\mathrm{Kgs} / \mathrm{m}^{3}\right)$ with $10 \%$ POBC containing hooked-end steel fibers

\begin{tabular}{|c|c|c|c|c|c|c|}
\hline $\begin{array}{c}\% \text { of } \\
\text { Hooke } \\
\text { d-end } \\
\text { steel } \\
\text { fibers }\end{array}$ & 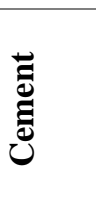 & 胥 & ن & U & 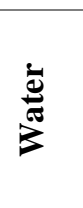 & 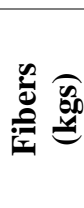 \\
\hline 0 & 18.24 & 37.84 & 28.62 & 3.78 & 9.12 & 0 \\
\hline 0.2 & 18.24 & 34.06 & 28.62 & 3.78 & 9.12 & 0.19 \\
\hline 0.4 & 18.24 & 34.06 & 28.62 & 3.78 & 9.12 & 0.37 \\
\hline 0.6 & 18.24 & 34.06 & 28.62 & 3.78 & 9.12 & 0.56 \\
\hline
\end{tabular}

Table 2 The Specimen casted for compressive and flexural strength

\begin{tabular}{ccccc}
\hline \multirow{2}{*}{$\begin{array}{c}\text { of } \\
\text { Hooked-end } \\
\text { steel fibers }\end{array}$} & \multicolumn{2}{c}{ 7 days } & \multicolumn{2}{c}{ 28 days } \\
\cline { 2 - 5 } & $\begin{array}{c}\text { Comp. } \\
\text { Test }\end{array}$ & $\begin{array}{c}\text { Flex. } \\
\text { Test }\end{array}$ & $\begin{array}{c}\text { Comp. } \\
\text { Test }\end{array}$ & $\begin{array}{c}\text { Flex. } \\
\text { Test }\end{array}$ \\
\hline 0 & 3 & 3 & 3 & 3 \\
\hline 0.2 & 3 & 3 & 3 & 3 \\
\hline 0.4 & 3 & 3 & 3 & 3 \\
\hline 0.6 & 3 & 3 & 3 & 3 \\
\hline Sub Total & 12 & 12 & 12 & 12 \\
\hline Total Samples & & \multicolumn{3}{|c}{} \\
\hline
\end{tabular}

\section{Results and Discussion}

Collected POBC were evaluated for the physical properties and results are provided in Table 3.

Table 3 Physical properties of POBC

\begin{tabular}{cc}
\hline Property of material & Value \\
\hline Specific gravity & 2.06 \\
\hline Sieve analysis & Zone of aggregates - Zone I \\
\hline
\end{tabular}

The particle size distribution results are provided in Fig. 3. It is demonstrated that the sand and POBC are in the range of the upper and lower limits. Furthermore, the pattern of size distribution graph for sand and POBC are in the same size. The total percentages of sand and POBC passed through $5 \mathrm{~mm}$ sieve were 95 to $99 \%$. Moreover, there was $2 \%$ and $0.67 \%$ of sand and POBC particles passed through $0.063 \mathrm{~mm}$ sieve respectively. Thus, it can conclude that sand has finest particles than POBC and similar results have been noticed in the previous studies [4] [16].

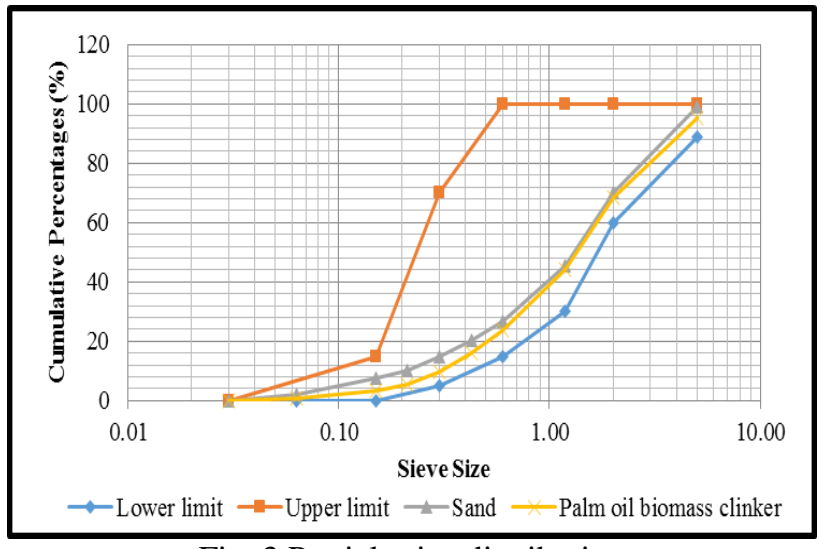

Fig. 3 Particle size distribution

The workability of concrete was measured, and the results are provided in Fig. 4. The results are indicated that the slump value was decreased with the increment of hooked-end steel fibers. The decrement of workability of concrete due reduction in mobility of material and fibers creates blocking to the relative movement of the aggregates [27]. Therefore, it restrained the concrete mixtures from segregation and flow and lower slump was observed with the increase proportion of steel fibers in the concrete. Comparable results have been noticed in the previous studies [20] [27]. 


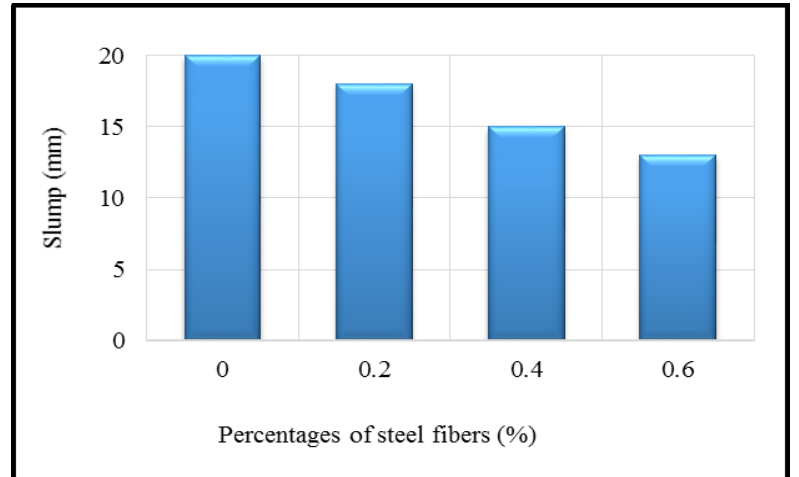

Fig. 4 The slump values of POBC-concrete with steel fibers

The compressive strength was investigated through concrete cubes containing $10 \%$ of POBC with varying percentage of hooked-end steel fibers. The average results for compressive strength are provided in Fig. 5. The result shows that the compressive strength tends to decrease with the addition of hooked-end steel fibers. The maximum compressive strength was recorded as 26.01 $\mathrm{MPa}$ and 27.51 MPa with $0.6 \%$ inclusion of hooked-end steel fibers at 7 days and 28 days respectively. The concrete compressive strength declines due to the unevenly distribution and improper orientation of hooked-end steel fibers [18]. Thus, it unable to resist the propagation of crack and reduced the concrete strength.

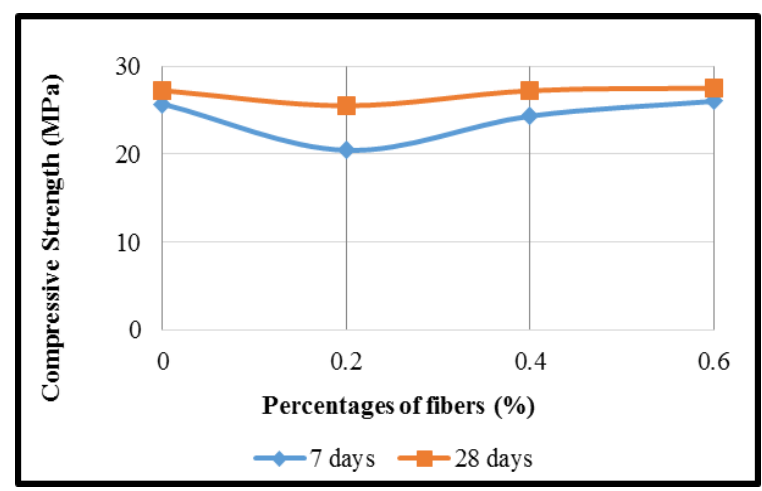

Fig. 5 Compressive strength of POBC-concrete with steel fibers

Apart from the compressive strength, the flexural strength of concrete containing $10 \%$ POBC with varying percentage of hooked-end steel fibers were also investigated in this research and results are demonstrated in Fig. 6. The maximum flexural strength in concrete was recorded as $2.23 \mathrm{MPa}$ and $2.54 \mathrm{MPa}$ at 7 days and 28 days respectively with $0.4 \%$ inclusion of hooked-end steel fibers. The growth of flexural strength due to the capability of hooked-end steel fibers in releasing the fracture energy around the crack tips [21]. But beyond the $0.4 \%$, reduction of flexural strength was observed, however it is still higher than the control specimen. This situation happens due to low fibers content in the critical area was led to the unacceptable reduction of strength.

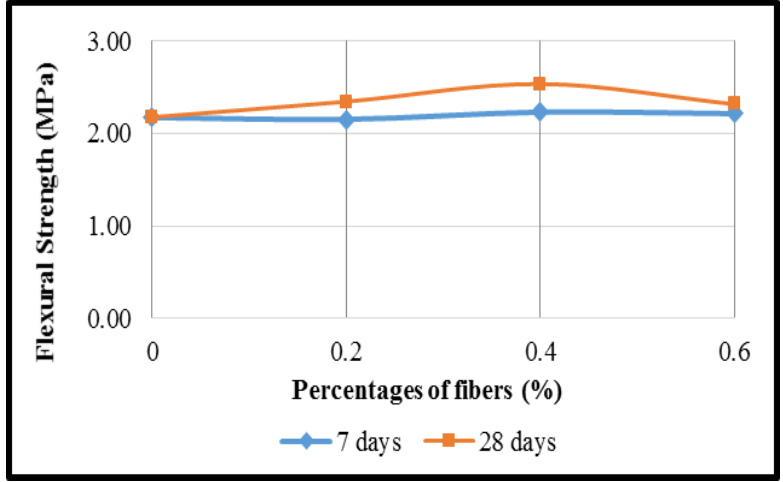

Fig. 6 Flexural strength of POBC-concrete with steel fibers

\section{Conclusion}

Based on the experimental results fallowing conclusions have been drawn:

i. The concrete with $10 \%$ POBC as sand replacement along with hooked-end steel fibers, decreases concrete workability.

ii. The maximum compressive strength was recorded as 26.01 $\mathrm{MPa}$ and $27.51 \mathrm{MPa}$ with $0.6 \%$ inclusion of hooked-end steel fibers at 7 and 28 days respectively.

iii. Compressive strength tends to decrease with the addition of hooked-end steel fibers. The compressive strength of concrete declines may be due to the unevenly distribution and improper orientation of hooked-end steel fibers.

iv. The maximum flexural strength in concrete was recorded as $2.23 \mathrm{MPa}$ and $2.54 \mathrm{MPa}$ at 7 days and 28 days respectively with $0.4 \%$ inclusion of hooked-end steel fibers.

Therefore, it was concluded that the hooked-end steel fibers have good potentiality to enhance the compressive as well as flexural strength of concrete but appropriate mixing of concrete and proper distribution of hooked-end steel fibers should be ensured.

\section{Acknowledgement}

The authors of this research are gratefully acknowledged the Universiti Tun Hussein Onn Malaysia (UTHM) for the funds and facilities provided for this research.

\section{References}

[1] ACI Committee 209, "Guide for Modeling and Calculating Shrinkage and Creep in Hardened Concrete," 2008.

[2] A. Hamid Mir, "Replacement of Natural Sand with Efficient Alternatives: Recent Advances in Concrete Technology," J. Eng. Res. Appl. www.ijera.com, 2015.

[3] K. S. Al-Jabri, M. Hisada, S. K. Al-Oraimi, and A. H. Al-Saidy, "Copper slag as sand 
replacement for high performance concrete," Cem. Concr. Compos., vol. 31, no. 7, pp. 483488, Aug. 2009.

[4] W. M. Ibrahim $\mathrm{H}$ et al., "Compressive and flexural strength of concrete containing palm oil biomass clinker and polypropylene fibres," IOP Conf. Ser. Mater. Sci. Eng. Pap., vol. 271, no. 108, 2017.

[5] F. Abutaha, H. Abdul Razak, and J. Kanadasan, "Effect of palm oil clinker (POC) aggregates on fresh and hardened properties of concrete," Constr. Build. Mater., 2016.

[6] B. Balakrishnan and A. S. M. A. Awal, "Durability properties of concrete containing high volume Malaysian fly ash," Int. J. Res. Eng. Technol., vol. 03, no. 04, pp. 529-533, 2014.

[7] M. Rafieizonooz, J. Mirza, M. R. Salim, M. W. Hussin, and E. Khankhaje, "Investigation of coal bottom ash and fly ash in concrete as replacement for sand and cement," Constr. Build. Mater., vol. 116, pp. 15-24, Jul. 2016.

[8] H.-K. Kim, "Utilization of sieved and ground coal bottom ash powders as a coarse binder in high-strength mortar to improve workability," Constr. Build. Mater., vol. 91, pp. 57-64, Aug. 2015.

[9] S. A. Mangi, M. H. Wan Ibrahim, N. Jamaluddin, M. F. Arshad, and R. Putra Jaya, "Short-term effects of sulphate and chloride on the concrete containing coal bottom ash as supplementary cementitious material," Engineering Science and Technology, an International Journal, 2018.

[10] M. H. W. Ibrahim, A. F. Hamzah, N. Jamaluddin, P. J. Ramadhansyah, and A. M. Fadzil, "Split Tensile Strength on Self-compacting Concrete Containing Coal Bottom Ash," Procedia - Soc. Behav. Sci., vol. 195, pp. 2280-2289, 2015.

[11] P. J. Ramadhansyah, B. H. Abu Bakar, M. J. Megat Azmi, and M. H. Wan Ibrahim, "Engineering properties of normal concrete grade 40 containing Rice husk ash at different grinding times," Int. J. Technol., vol. 2, no. 1, pp. 10-19, 2011.

[12] R. P. Jaya, B. H. A. Bakar, M. A. M. Johari, and M. H. W. Ibrahim, "Strength and permeability properties of concrete containing rice husk ash with different grinding time," Cent. Eur. J. Eng., vol. 1, no. 1, pp. 103-112, 2011.

[13] S. Rukzon, P. Chindaprasirt, and R. Mahachai, "Effect of grinding on chemical and physical properties of rice husk ash," Int. J. Miner. Metall. Mater., vol. 16, no. 2, pp. 242-247, 2009.

[14] A. Chaipanich and W. Wongkeo, "Ternary Blends of Portland Cement, Bottom Ash and Silica Fume: Compressive Strength of Mortars and Phase Characterizations," Chiang Mai J. Sci. Chiang Mai J. Sci, vol. 41, no. 412, pp. 424-434, 2014.

[15] M. K. Dash, S. K. Patro, and A. K. Rath, "Sustainable use of industrial-waste as partial replacement of fine aggregate for preparation of concrete - A review," International Journal of Sustainable Built Environment. 2016.

[16] M. Soofinajafi, P. Shafigh, F. W. Akashah, and H. Bin Mahmud, "Mechanical Properties of High Strength Concrete Containing Coal Bottom Ash and Oil-Palm Boiler Clinker as Fine Aggregates," MATEC Web Conf., 2016.

[17] P. Shafigh, H. Bin Mahmud, M. Z. Bin Jumaat, R. Ahmmad, and S. Bahri, "Structural lightweight aggregate concrete using two types of waste from the palm oil industry as aggregate," J. Clean. Prod., 2014.

[18] A. S. El-Dieb, "Mechanical, durability and microstructural characteristics of ultra-highstrength self-compacting concrete incorporating steel fibers," Mater. Des., vol. 30, no. 10, pp. 4286-4292, Dec. 2009.

[19] S. C. Lee, J. H. Oh, and J. Y. Cho, "Compressive behavior of fiber-reinforced concrete with endhooked steel fibers," Materials (Basel)., 2015.

[20] S. Grünewald and J. C. Walraven, "Parameterstudy on the influence of steel fibers and coarse aggregate content on the fresh properties of selfcompacting concrete," Cem. Concr. Res., 2001.

[21] Ş. Yazici, G. Inan, and V. Tabak, "Effect of aspect ratio and volume fraction of steel fiber on the mechanical properties of SFRC," Constr. Build. Mater., 2007.

[22] P. Hawken, A. B. Lovins, and L. H. Lovins, "Natural Capitalism The Next Industrial Revolution," in Natural Capitalism, 1997.

[23] M. Aslam, P. Shafigh, and M. Z. Jumaat, "Oilpalm by-products as lightweight aggregate in concrete mixture: A review," Journal of Cleaner Production. 2016.

[24] S. H. Park, D. J. Kim, G. S. Ryu, and K. T. Koh, "Tensile behavior of ultra high performance hybrid fiber reinforced concrete," Cem. Concr. Compos., 2012.

[25] A. Khaloo, E. M. Raisi, P. Hosseini, and H. Tahsiri, "Mechanical performance of selfcompacting concrete reinforced with steel fibers," Constr. Build. Mater., 2014

[26] M. Imam, L. Vandewalle, F. Mortelmans, and D. Van Gemert, "Shear domain of fibre-reinforced high-strength concrete beams," Eng. Struct., 1997.

[27] A. D. de Figueiredo and M. R. Ceccato, "Workability Analysis of Steel Fiber Reinforced Concrete Using Slump and Ve-Be Test," Mater. Res., 2015. 